\title{
Will the conversion of evergreen and deciduous broad-leaved mixed forests to Chinese fir plantations affect the transportation of soil water?
}

\author{
qi Chen ${ }^{1}$, Yuanqiu Liu ${ }^{1}$, Jiahui Huang ${ }^{1}$, Yunhong Xie ${ }^{2}$, Tianjun Bai ${ }^{3}$, Xi Yuan ${ }^{1}$, Tianqi \\ Wang $^{4}$, Tingqi Xiao ${ }^{1}$, and Wenping Deng ${ }^{1}$ \\ ${ }^{1}$ Jiangxi Agricultural University \\ ${ }^{2}$ Beijing Forestry University \\ ${ }^{3}$ Lu Mount Forest Ecosystem Positioning Research Station \\ ${ }^{4}$ Shanxi Jingneng Lvlin Electric corporation limited
}

May 20, 2021

\begin{abstract}
The conversion of natural forests to planted forests has become a global trend, and the practice has wide-ranging effects on soil. This study aimed to explore the differences in soil water movement after the conversion of evergreen and deciduous broad-leaved mixed forests (natural forest, NF) to Chinese fir (Cunninghamia lanceolate (Lamb.) Hook.) plantations (CFP, 20-21 years old). Soil samples from five layers $(0-5,5-10,10-20,20-30$, and $30-50 \mathrm{~cm})$ were collected from NF and CFP before and after rainfall event in the Peng Chongjian watershed, Jiangxi Province. The physical properties of the soils, including the mean and coefficient of variation (CV) of soil moisture content and the soil particle composition, were determined in both forest types. The $\delta \mathrm{D}$ of soil water and the litter water-holding capacity were also measured. The results showed that the variation ranges of moisture content in each soil layer after the rainfall was $21.13 \%-49.40 \%$ in CFP and $21.33 \%-43.87 \%$ in NF. There were no significant differences in soil bulk density or porosity; the clay and silt contents were significantly increased in topsoil, while the sand was significantly decreased $(\mathrm{P}<0.05)$. After the rainfall, soil water in CFP responded more promptly than NF. In the process of infiltration, the contribution of rainfall to soil moisture gradually decreased with increasing soil depth. Topsoil $(0-5 \mathrm{~cm})$ in NF responded promptly to rainfall, but the response showed a lag effect with the increase of soil depth. With the extension of infiltration time, the contribution of precipitation to deep soil gradually increased. The results showed that the soil did not degrade after the conversion of NF to CFP, a significant guiding result for plantation cultivation.
\end{abstract}

\section{Hosted file}

manuscript.docx available at https://authorea.com/users/414804/articles/522730-willthe-conversion-of-evergreen-and-deciduous-broad-leaved-mixed-forests-to-chinese-firplantations-affect-the-transportation-of-soil-water

\section{Hosted file}

\begin\{CJK\}\{UTF8\}\{gbsn\}. \end\{CJK\}\selectlanguage\{english\}docx available at https://authorea. } com/users/414804/articles/522730-will-the-conversion-of-evergreen-and-deciduous-broadleaved-mixed-forests-to-chinese-fir-plantations-affect-the-transportation-of-soil-water

\section{Hosted file}

\begin\{CJK\}\{UTF8\}\{gbsn\}. \end\{CJK\}\selectlanguage\{english\}docx available at https://authorea. } com/users/414804/articles/522730-will-the-conversion-of-evergreen-and-deciduous-broad- 
leaved-mixed-forests-to-chinese-fir-plantations-affect-the-transportation-of-soil-water 